\title{
ENGLISH FOR SPECIFIC PURPOSES IN THE HOSPITALITY INDUSTRY
}

\author{
Kamo Chilingaryan \\ Mr., RUDN University, RUSSIA, chili1@yandex.ru
}

\begin{abstract}
Over the past decade, the hospitality industry has been developing at an unusually rapid pace. Tourism is a way to discover the world and the most promising area of the economy, contributing to international contacts' intensification and the expansion of intercultural relations. However, the labor market has a great need for professionally trained, highly qualified managers and business professionals who must have excellent language command and be good at management, tourism, and economics. Language is an integral part of the human mind and, therefore, only the interaction of all mental structures and processes (perception, understanding, memory) ensures its functioning.
\end{abstract}

A foreign language should become a tool for understanding world cultures. However, the issue of a foreign language's significance and goals in hospitality industry managers' professional activity remains insufficiently covered.

Given this, a professionally-oriented approach to teaching foreign languages provides for developing students' foreign language communication skills. For hospitality industry professionals, the prerequisites for successful professional activity are the awareness of the communication process features, possession of verbal and non-verbal communication techniques, communicative strategies, and communicative competence, including the ability to use a foreign language to achieve professionally significant goals. As for the goals of teaching a foreign language, it is worth noting that this is a pre-planned result of the pedagogical activity, which can be achieved using such components of training as content, methods, conditions, teaching aids, and alike, which are formed under the influence of the society's order and affect other components of training.

Teaching a foreign language is not only the assimilation of a particular lexical, grammatical, and syntactic material but the simultaneous combination of language elements with elements of culture in teaching.

The mastery of a foreign language follows the path opposite to that of native language development. Therefore, we can say that the native language development goes from the bottom to up, while foreign language skills go from the top to down.

Hospitality is the sphere of human activity in which communication is the most important. Therefore, practical knowledge of a foreign language is fundamental in future hospitality industry specialists' professional activities.

Keywords: hospitality, language command, international communication

\section{INTRODUCTION}

\subsection{Foreign Language in the Hospitality Industry}

The term ESP (English for Specific Purposes) is devoted to teaching English, including Business English, Technical English, English for the hospitality industry, and many others. 
In Maslow's Hierarchy of Needs, where some characteristics [1] can be named absolute, ESP is explained as the underlying methodology and activities of the discipline it serves. Moreover, ESP is focused on the language relevant to specific activities in terms of grammar, lexis, register, study skills, discourse, and genre.

Having mentioned absolute, one shall not forget variable characteristics that include relation to or designation for specific disciplines, usage in specific teaching situations. We cannot teach ESP at schools: it serves the purposes of advanced students. If students' motivation and expectations are demanding, then it is necessary to design ESP courses that can best prepare learners for future professional communication. The ESP student is well trained in the subject-matter field. A foreign language (English in our case) is presented in authentic contexts, helping the learners better understand the particulars of the language used in their relevant fields. [11]

The term "hospitality" and the accompanying business sector - the hospitality industry - deserve special attention. The hospitality industry is a collective concept for numerous and diverse entrepreneurship forms, specializing in services related to guests' reception and servicing.

The hospitality industry is closely connected with foreign languages. Every year the number of travelers is increasing. It is impossible to travel around the world and not know foreign languages. Nevertheless, most travelers speak only one language and do not intend to stay at home. [12] It is a branch of the non-material sphere economy, the enterprises that satisfy the needs of tourists in material and non-material services, the primary function of which is to provide a person with a full and rational rest. Tourism is the fundamental basis of the economy of many developed and developing countries. It has currently turned into an international scale industry, ranking by income third among the most significant export sectors of the economy, second only to the oil industry and the car industry. [8]

Tourism is understood as one of the forms of population migration that is not associated with a change of residence or work. The need for its definition arose in the first half of the XX century and was due to the widespread increase in tourist flows, the growing economic importance of tourism, and as a result, the attempts of statistical accounting of travelers.

International tourism today in many countries has turned into a booming industry. Currently, every 7th job in the world falls on the tourism business. According to the WTO (World Tourism Organization) forecasts, by 2020 , the number of international tourist arrivals would have been 1.6 billion, which is three times higher than in 2000. However, the COVID pandemic stopped it. The daily expenses of tourists, excluding air travel, might have grown to $\$ 5$ billion per day.

Currently, international tourism has received significant development and has become a massive socioeconomic phenomenon globally. Its rapid development is facilitated by expanding political, economic, scientific, and cultural ties between states and peoples.

The hospitality industry is one of the large and rapidly developing systems of the economy. The hospitality industry is not only an individual approach to service. It includes advanced technologies for quick processing and order submission, providing well-coordinated technical issues in customer service (Internet access, highquality telephone service, affordable long-distance, and international tariffs), and customer pre-determining desires. Every guest likes it when he is taken care of, and his possible wishes are foreseen? Hospitality enterprises' owners should do their best to please the client [11].

If the teacher understands the students' targets, he/she can easily distinguish the students' needs in ESP. These targets include the writing and speech that learners are required to produce and understand in specific contexts). The first thing to know is some professional information about the learners, i.e., target situation analysis, and objective needs.

Another critical point is the students' personal needs, which may affect the way they learn, such as previous learning experiences (positive or negative, their causes), cultural information (why? what for?), reasons for attending the course and what they expect of it, and of course, the learners' attitude to English.

After identifying the students' needs and objectives, we turn to their current skills and language. It is here that the teacher faces the gap between these points.

The teacher needs to know how language and skills are used in the target situation. The latter will mean linguistic analysis, discourse analysis, genre analysis. The teacher should know what is wanted from the course and have a thorough understanding of its environment.

Undoubtedly, general English "content should also be integrated into the course since content-related language cannot function without general English language content" [10]. 
English is one of the most significant languages in the world. Nowadays, English is used as the primary language for international communication. Even in the field of advertising in Russia, more and more companies are choosing English-language names, slogans, and logos [3].

Such a popularization of the language suggests that knowledge of English in the modern world is almost mandatory. It removes the language barrier when traveling. In the business world, its importance is even greater. Only fluency in English will allow us to apply for positions in leading Russian and foreign companies, develop or open one's own business abroad. In the hospitality industry, English also plays an important role. Since this language is nowadays international and generally accepted, English language knowledge is essential for those who work in tourism and hospitality, not only for everyday tasks but also for career advancement.

The increased demand and accessibility of trips abroad and globalization's intensive process require good language command for the hospitality industry personnel. The formation of the global economy creates the interdependence of the economies of states. The development of the Internet leads to communication between representatives of different nations; knowledge of communicative features helps to better understand each other, significantly complementing the knowledge of the language.

The pace of language learning depends on the group(s) level and objectives. Having clarified the students' objectives and needs, they should be involved in project doing, participating in presentations, conferences, and other events where public speaking is a must. Assignments and tests are done in writing (paper) and electronic. During the semester, students write two pairs of tests - preliminary and final.

As Dudley suggests, two crucial issues should be highlighted: assessment and evaluation. Assessment measures what learners know and what they can do, whereas evaluation reveals how well the ESP works with more successful factors and modifying less successful aspects [1].

Unlike General English that is focused on teaching grammar and language structures, ESP concentrates more on language in context. It can be stated that General English serves as a bridge to ESP. While in English as a Second Language, all four language skills - listening, reading, speaking, and writing, are stressed equally, in ESP it is the needs analysis that determines which language skills are most needed [5].

\subsection{The Role of a Foreign Language in the Global World}

In the XXI century, UNESCO proclaimed that the whole civilized world strives for openness and mutual understanding as the century of polyglots.

In this regard, the role and significance of the study of foreign languages are growing. It becomes essential to educate a person who will be willing to participate in intercultural communication in a foreign language. The basis of being and thinking of the XXI century is the dialogue of various cultures. As an educational subject, a foreign language has a very effective means of educating a culture. It is essential to use a foreign language's full educational potential that promotes students' familiarization with world culture and a better awareness of their culture.

Factors of the native sociocultural environment play an essential role in forming impressions about the country of the studied language. Any national culture is an integral part of world culture.

A foreign language is historically the most important subject of general education. However, its educational and developing reserves have not yet been studied thoroughly. Its understanding boils down to the fact that the study of a foreign language lays the foundation for foreign language verbal activity. Language is an additional means of broadening one's horizons. With the study of the native language, a foreign language helps to understand the universal verbal communication methods better and promotes the upbringing of a person's moral qualities [7].

There are several reasons to study a foreign language and, in our case, English. First, a career. To get a prestigious job in a large organization, fluency in the language is necessary. It is explained by the fact that large organizations have foreign enterprises among their suppliers and buyers, and, accordingly, negotiations, transactions, signing of contracts, and alike, are carried out in a foreign language.

Secondly, trips abroad. Everyone knows that a modern, versatile, and inquisitive person seeks to visit as many different countries and cities as possible to get acquainted with other peoples' cultures and customs. The knowledge of English improves the quality of service for visitors and attracts more and more tourists.

Thirdly, it is education. Knowledge of English makes it possible to study at prestigious foreign universities, as it is one of the most important admission criteria. 
Next, come the books. Reading books in the original language, one can get a lot more enjoyment from reading.

ESP in the hospitality industry aims at full preparation of the students for their future careers. They are highly likely to seek employment in international companies where English is widely spoken or used as a medium of communication.

By the end of the course, students should know hospitality industry terminology and write competently in English, e.g., memos, e-mails, minutes, answer the clients' complaints, and many others. They must understand and conduct a general specific conversation and maintain relationships with the target community.

What we include into the objectives, are listening (to understand relevant conversations); speaking (to communicate effectively with native speakers in job interviews as well as business matters settings, having initial interviews with clients); reading (to understand a variety of texts, such as travelogues, brochures, documents); writing (to be able to persuasive writings, resumes, and e-mails, client-oriented correspondence).

An educator's mission is not only language supervising (which is essential) and understanding what teaching is. This challenge should be well understood by any teacher before he/she starts doing ESP. We do much brainstorming in English settling cases (client-guest, for example) when students notice that their perspective is appreciated and assessed.

The teacher should be extremely attentive to students when arranging them for group tasks: they may have their preferences. Nevertheless, for the reason of future team-builders, we sometimes treat them the wrong way.

One factor should never be lost from view: some students are not motivated to learn ESP. They consider it to be a variety of English, with just professionalisms to be learned. This wrong view may provoke a reluctant attitude when writing, listening, or speaking comprehension are damaged due to the task's seeming ease.

As Hewings states, 'The main underlying motivation for papers on text/discourse analysis is the needs analysis, they can be established by examining by targets (the writing and speech that learners are required to produce and understand in specific contexts) or the gap between what the learners can do at a particular stage of their studies and what will eventually be required of them.' [4].

Is there a difference between the approaches to teach ESP and General English? Hutchinson [6] says that 'in theory nothing, in practice a great deal.' Now we know for sure that needs analysis should be carried out to determine what was necessary to achieve the purpose of studying English.

We approach a fundamental question. We have found the students' needs. Does it mean we should teach what the students want? One must remember the curriculum, the institutional requirements, and guidelines, thus, integrating these components: students' needs and institutional guidelines. Nunan D. [9] explains how to describe the objectives clearly. Depending on these objectives, they may sound like:

- Students will learn that

- Students will be aware of

- Students will develop

It is the teacher who acts as a source of information, of course, if he/she is eager to contribute to the achievable goals. The author has had some experience working with such colleagues who seemed to think that GE and ESP were the same and had a shallow understanding of their (teachers') mission.

Graves considers that teaching materials are "tools that can be figuratively cut up into component pieces and rearranged to suit the students' needs, abilities, and interests in the course [2]. In short, rearranging some old materials, one may achieve the goal. Do we need to take into account the learners' needs? It is the bravest thing to do. It means you are open-minded and ready to implement those comments later.

Since the student generation differs, you need to develop a new program or ament the old one to meet newcomers' requirements. The moment you think that English remained the same and only the students change - this is your degrading start.

In short: be flexible, since course development is an on-going process. 


\section{DISCUSSIONS AND CONCLUSION}

A few years ago, English was perceived by all as foreign. Nevertheless, over time, the English language's role has grown so much that it is now considered worldwide international.

English is the language of business. All prominent businessmen who want to enter the international market need to be fluent in English.

Most computer programs and applications are written again in English. [12] When traveling, staying in a hotel, as in a temporary home (home away from home), the guest expects to get into a pleasant atmosphere, not to experience difficulties in communication, and if necessary - to receive help and information. He is understood, and he understands the speech in another country.

Summing up the general result, we note that English is an essential component in a modern person's life, and everyone can find for themselves more than one reason for studying it and improving their skills.

Factors contributing to the study of foreign languages:

- Work - knowledge of a foreign language will help find a more promising job, get a promotion, and go on a business trip to another country.

- Science - Without knowing foreign languages, it is impossible to get acquainted with foreign sources and interact with foreign colleagues.

study

- Emigration.

- Religion

- Personal motives, i.e., international marriages, communication with foreign friends, hobbies

Travels.

Confident knowledge of a foreign language means new opportunities in the international market!

\section{ACKNOWLEDGEMENT}

The work has been prepared under the RUDN University " 5 top 100 " program.

\section{REFERENCE LIST}

[1] Dudley E., T.; St John, M.J. (1998) Developments in English for Specific Purposes: A multi-disciplinary approach. Cambridge: Cambridge University Press,

[2] Graves, K. (1996) Teachers as course developers. England: Cambridge University Press,

[3] Gromov A.Z. ( 2012), Job description of a hotel manager, p.123

[4] Hewings, M. A. history of ESP through English for specific purposes http://www.espworld.info/Articles3/Hewings.paper.htm

[5] http://www.usingenglish.com/articles/teaching-english-for-specific-purposes-esp.html

[6] Hutchinson, T.; Waters, A. (1987) English for Specific Purposes: A learner-centered approach. Cambridge University Press,

[7] Layko M.Yu., Rodionov A.S. (2009) Once again about the staff. Who is right: hotels or universities? Hotel Parade, p. 34

[8] Matskivskaya Yu. (2012) What's for tea? Shop equipment in Russia, p 178

[9] Nunan, D. (1988) Syllabus Design. Oxford: Oxford University Press,

[10] Yong Chen. From Common Core to Specific, Chong Qing University, P.R. of China. 
Proceedings of ADVED 2020- 6th International Conference on Advances in Education 5-6 October 2020

http://www.asian- esp-iournal.com/June 2006yc.php. https://www.asian-esp-journal.com/june-2006/

[11] Zorin I.V., Kvartalnov V.A. (2011) Tourism as an activity, Moscow, Finance and statistics, p. 134

[12] Zorin I.V., Kvartalnov V.A. (2001) Tourism as an activity, Moscow, Finance and statistics, p. 157 